\title{
Recent Advances in Ketamine Research: An Update
}

\author{
Yuba Raj Thapa, Quan Ren* \\ Department of Anesthesiology, Zhongda Hospital, School of Medicine, Southeast University, Nanjing, China \\ Email: ${ }^{*}$ _quanren@yahoo.com
}

How to cite this paper: Thapa, Y.R. and Ren, Q. (2020) Recent Advances in Ketamine Research: An Update. Open Journal of Anesthesiology, 10, 89-100. https://doi.org/10.4236/ojanes.2020.103008

Received: March 1, 2020

Accepted: March 28, 2020

Published: March 31, 2020

Copyright (c) 2020 by author(s) and Scientific Research Publishing Inc. This work is licensed under the Creative Commons Attribution International License (CC BY 4.0).

http://creativecommons.org/licenses/by/4.0/ (c) (i) Open Access

\begin{abstract}
Ketamine is a sedative $\mathrm{N}$-methyl-D-aspartate receptor antagonist, considered as a dissociative anesthetic medication. Ketamine inhibits the voltage-gated $\mathrm{Na}^{+} \& \mathrm{~K}^{+}$channels and serotonin and dopamine re-uptake and affects specific receptors, such as $\alpha$-amino-3-hydroxy-5-methyl-4-isoxazolepropionic acid (AMPA), kainate and aminobutyric acid A receptors. It is commonly administered by a parenteral route. On administration, ketamine has particular properties that are potentially involved during anesthetic induction including the enhancement of descending inhibition and anti-inflammatory effects. Recent literature reviews report that ketamine possesses various clinically beneficial properties. Sub-dissociative dose/Lower dose of ketamine (LDK) has potential as well as safe effects in clinical practice for the management of acute and chronic pain in postoperative room as well as Emergency Department (ED), along with cognitive function and depression in Psychiatric Department. Moreover, pharmacology of ketamine includes bronchodilators, neuro-protective actions, anti-shock, anti-suicide, and anti-tumor action immune system disorder. The purpose of this review is to illustrate recent advances in mechanism of action, mode of administration and indication of clinical uses of ketamine. In this article various new uses of ketamine have been shown, mainly related to its NMDAR antagonism and the clinical implementation and significance of low dose/sub dissociative dose of ketamine. In future, beyond being used as the adjuvant general anesthesia, it also can be used as a rapid acting antidepressant and anti-suicidal agent for mental disorders, and adjuvant analgesia to avoid potential risk and side effects of opioids in emergency department and in post-operative care.
\end{abstract}

\section{Keywords}

Ketamine, Dissociative Anesthesia, Sedative, Pain Management, 
Anti-Depressant Agent, Pediatrics Anesthesia

\section{Introduction}

Ketamine was first synthesized as a phencyclidine derivative in 1962 by Claying Stevens, and first used in 1965 by Domino and Corssen. In 1966 ketamine was studied for the first time among 130 patients aged from 1.5 months to 86 years. The study illustrated adverse effects and no emergence phenomena which produces "dissociative anesthesia", characterized by evidence on the EEG dissociation between thalamocortical and limbic System. Ketamine binds noncompetitively to the phencyclidine, binding site of NMDA ( $N$-methyl-d-aspartate Antagonist) receptors, but also modifies them via allosteric mechanisms. In 1970, the US Food and Drug Administration (FDA) approved ketamine for the first time for human use. Ketamine isdescribed as a "Unique Drug" which has potency of hypnotic, analgesic and amnesic effects which makes it ideal for mass casualty events, burn management, and the gunshot victim. Ketamine is considered as an essential medicine by WHO for limited-resource settings for its potency as an anesthetic, analgesic and low incidence of cardiorespiratory adverse effects [1] [2] [3]. Glutamate $N$-methyl-d-aspartate receptor (NMDA-R) antagonist ketamine, may also stimulate opioid, dopamine, norepinephrine, serotonin, and muscarinic cholinergic receptors. Ketamine is a sedative medication that reduces pain by diminishing central sensitization, hyperalgesia and "wind up" phenomenon, however originally developed for the induction and maintenance of anesthesia in adults. It has a 2.5 -h of plasma elimination time. A recent advance in ketamine research is because of availability of $S(+)$ ketamine. $S(+)$ ketamine has chiral center at the carbon 2 atom of the cyclohexanon ring, and therefore exists as the optical stereoisomers $\mathrm{S}(+)$ and $\mathrm{R}(-)$ ketamine. Though duration of action is shorter, $\mathrm{S}(+)$ ketamine has a fourfold greater affinity for NMDA receptors than does $\mathrm{R}(-)$ ketamine. This difference results in a clinical analgesic potency of $\mathrm{S}(+)$ ketamine approximately two times greater than that of racemic and four times greater than that of $\mathrm{R}(-)$ ketamine. Ketamine can be administered intravenously (most common), intramuscularly (93\% bioavailability (BA)), intranasally (50\% BA), intrarectally $(25 \% \mathrm{BA})$, and orally $(20 \% \mathrm{BA})$. Ketamine administration in a sub-dissociative dosing range $(0.1-0.3 \mathrm{mg} / \mathrm{kg})$ leads to anti-hyperalgesia, anti-allodynia, and anti-tolerance, making it useful in managing a variety of acute and chronic painful conditions without adversely affecting hemodynamics and cognition. In addition to its role as anesthesia and analgesia, pharmacological model of ketamine is safe and tolerable in nature for the core symptoms of schizophrenia, and prototype for a new generation of antidepressants after the discovery of its profound and rapid effects on depressive symptoms. Ketamine is NMDA receptor antagonist, when this receptor gets blocked glutamate preferentially interacts with AMPA receptor, it is augmented through cortical neuronal pathway, which is essential for antidepressant effect of ketamine [1] [2] [3] [4] [5]. 


\section{Mechanism of Action, Pharmacokinetics and Mode of Administration}

The term "ketamine" is a collective term for the terms "ketone" and "amine" [6]. Phenylpiperidine derivative ketamine is structurally related to phencyclidine (PCP) with 2(2-chlorophenyl)-2-(methylamino)-cyclohexanone and it is hydrochloride salt which is available in both powdered and aqueous forms, with the molecular formula $\mathrm{C}_{13} \mathrm{H}_{16} \mathrm{CINO}$ (Figure 1) and a molecular mass of 237.725 g/mol. Non-competitive NMDA receptor antagonist ketamine was first administered to human in 1966 [6]-[13]. Ketamine has a chiral center $r$ in the cyclohexanone ring. The racemic (50:50) mixture is composed of two enantiomers $\mathrm{R}(-)$ and $\mathrm{S}(+)$ optical stereoisomers. Both of these enantiomers bind with NMDA receptors whereas the $\mathrm{S}(+)$ variant isomer $\mathrm{S}(+)$ ketamine (esketamine or Ketanest STM) binds NMDA receptors with affinity of two times greater than racemic mixture and four times greater than that of $\mathrm{R}(-)$. In human $\mathrm{S}(+)$ ketamine has shown to be more potent anesthetic agent and analgesic, in comparison with the racemic product, whereas the $\mathrm{R}(-)$ enantiomer has greater efficacy as an antidepressant [1] [7]-[12]. Effects of ketamine are dependent on its dose. In high dose (Table 1) (IV 1 - $2 \mathrm{mg} / \mathrm{kg}$ ) ketamine produces a "dissociative anesthesia" or cataleptic state (i.e. eye open with general maintain of corneal, cough and swallow reflexes), whereas in low dose (IV 0.2 - $1 \mathrm{mg} / \mathrm{kg}$ (Table 1 ) infusion or bolus) ketamine acts as an analgesic and rapid acting anti-depressant, and reduces or delays opioids-induced tolerance and hyperalgesia. Low dose ketamine blocks NMDA receptors and regulates central sensitization, thus providing anti-hyperalgesia. Therefore, by reducing the amounts of opioids required, ketamine may play a role in acute postoperative pain management [12] [14]. Ketamine is highly lipid soluble and rapidly distributed to brain and other well perfused tissue. It is a cytochrome P450 dependent drug. Ketamine is redistributed to muscles and peripheral tissues, and ultimately to fat in the process of tissue perfusion with redistribution half-life of 7 - $15 \mathrm{~min}$ (clearance $15 \mathrm{ml} / \mathrm{kg} / \mathrm{min}$ ) and with elimination half-life period 2 - 4 hours. It rapidly passes BBB (blood-brain barrier), which ensure a rapid onset of acute analgesic effect. It is metabolized by CYP3A4, CYP2B6 and CYP2C9 in the liver to nor-ketamine(via N-demethylation) and then metabolized to 4-, 5- and 6-hydroxyl ketamine (through CYP2A6 and CYP2B6)

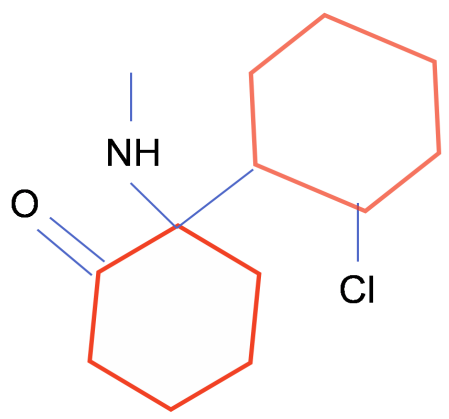

Figure 1. Molecular Formula: $\mathrm{C}_{13} \mathrm{H}_{16} \mathrm{ClNO}$. 
Table 1. Administration route and doses.

\begin{tabular}{|c|c|}
\hline Route of administration & Doses \\
\hline Per Oral [16] & $\begin{array}{l}\text { Children:3 }-15 \mathrm{mg} / \mathrm{kg} \\
\text { Adults: } 10 \mathrm{mg}-30 \mathrm{mg}(500 \mathrm{mg} \text { maximum })\end{array}$ \\
\hline Intravenous (IV) [8] [9] [12] [14] [15] & $\begin{array}{c}\text { Bolus: } \\
\text { Adults: } 1-2 \mathrm{mg} / \mathrm{kg} \\
\text { Children: } 0.25-2 \mathrm{mg} / \mathrm{kg} \\
\text { Infusion: } \\
\text { Adults: } 0.25-1 \mathrm{mg} / \mathrm{kg} / \mathrm{min} \\
\text { Children: } 2-6 \mathrm{mg} / \mathrm{kg} / \mathrm{min} \\
\text { LDK } \\
\text { Bolus: } \\
\text { Adults: } \leq 1 \mathrm{mg} / \mathrm{kg} \\
\text { Infusion } \\
\text { Adults: } 0.1-0.5 \mathrm{mg} / \mathrm{kg} / \mathrm{min}\end{array}$ \\
\hline Intramuscular (IM) [16] & $\begin{array}{c}4-5 \mathrm{mg} / \mathrm{kg} \\
8-10 \mathrm{mg} / \mathrm{kg}\end{array}$ \\
\hline Intrathecal [17] & $0.5-1 \mathrm{mg} / \mathrm{kg}$ (adult) \\
\hline Intranasal [18] [19] & $\begin{array}{c}0.25-4 \mathrm{mg} / \mathrm{kg} \\
3-9 \mathrm{mg} / \mathrm{kg}\end{array}$ \\
\hline
\end{tabular}

from nor-ketamine. Nor-ketamine, the hydroxy nor-ketamine (after glucuronidation) and unmetabolized ketamine are eliminated through bile and kidney. Pharmacological model of ketamine is safe and tolerable in nature for the core symptoms of schizophrenia, and prototype for a new generation of antidepressants after the discovery of its profound and rapid effects on depressive symptoms. Ketamine is NMDA receptor antagonist, when this receptor is blocked, glutamate preferentially interacts with AMPA receptor, it is augmented through cortical neuronal pathway, which is essential for antidepressant effect of ketamine [3] [4] [6] [12]. For surgical anesthesia use, ketamine hydrochloride is given intravenously or intramuscularly, along with these subcutaneous, epidural, transdermal and intra-articular, intranasal, oral and rectal are the alternate routes of administration. Lately preservative free ketamine as an inhalation anesthesia was tested to be rapid and safe in administration than IV, which seems very useful for geriatric cases and cancer patients, and is used in ED and in military set [7] [8] [11]. In chronic pain, ketamine is administrated through intranasal, oral and subcutaneous route. However, dose of ketamine depends upon route of administration (Table 1), ranging from single dose boluses (up to $1 \mathrm{mg} / \mathrm{kg}$ ) to continuous IV infusions (up to $0.18 \mathrm{mg} / \mathrm{kg} / \mathrm{h}$ for 48 hours postoperative) [15].

\section{Analgesic Action of Ketamine in Post-Operative Room}

Post-operative pain routinely resolves along with healing of the surgical wound; however, in some patient pain does not resolve long after surgery. Persistent post-operative pain (PPP, also referred as "chronic post-surgical pain") is common. This causes disability and lowers quality of life. Surgical factor such as du- 
ration and type of surgery, extent of intra-operative nerve damage and intensity as well duration of post-operative pain and patient factors such as demographic, psychosocial, and genetics play vital roles in development of PPP [20]. In recent studies, incidence of PPP is as high as $40 \%$ [13]. In postoperative pain, IV opioid is regular technique as a patient-controlled analgesia (PCA) but drowsiness, nausea and vomiting are adverse effects to opioids. Nociception stimulates the activation of N-methyl-D-aspartate (NMDA) receptor, which involves the pathophysiology of acute pain. Intravenous ketamine or intramuscular injection is used for surgical anesthesia and lower dose ketamine is newly used as postoperative anesthetic drug. Ketamine, a non-competitive NMDA antagonist, has specific NMDA blocking effect and regulates the central sensitization, hence provides anti-hyperalgesia effect. Systemic ketamine effectively reduced PACU pain intensity and analgesic demand. Because of multimodal analgesia quality, ketamine has been increasingly applied in the setting of postoperative pain [8] [10] [11] [13] [14] [21] [22]. In management of acute post-operative pain, ketamineadjuvant therapy has a significant effect on controlling the amounts of opioids demand (by inhibiting NMDA receptor-mediated pain facilitation), reduces opioids side effects such as post-operative nausea and vomiting (PONV), especially in patients who are particularly sensitive to adverse effects of opioids (such as the elderly), and improves the effectiveness of opioids and cardiopulmonary stability [8] [13] [14] [22] [23]. Low dose ketamine (LDK) or Sub-dissociative dose of ketamine (SDDK) reduces use of opioids in postoperative room by $40 \%$ with minimal side-effects. LDK means administration of no more than $1.2 \mathrm{mg} / \mathrm{kg} /$ hour of ketamine when used as continuous infusion and no more than $1 \mathrm{mg} / \mathrm{kg}$ when used as a bolus dose. For children or infants LDK is also used as a caudal analgesic adjuvant, which increases the duration of sensory block and improves pain relief in the post anesthesia care unit (PACU) without affecting pain scores. Data showed that caudal ketamine was effective in reducing the emergence pain and in increasing the duration of sensory block without influencing pain intensity [10]. There are no major complication and adverse effect seen on LDK IV infusion over the period of 48 hours [15] [23]. Along with post-operative pain management, LDK/SDDK infusion also has significant effects in neuropathy pain and palliative care management (cancer associated pain), in which patients who received LDK had major reduction of pain score over 2-hour over 15min infusion of Low Dose Ketamine [8] [21] (Table 1).

\section{Anti-Depression Action of Ketamine in Psychiatric Department}

Ketamine, an old widely used anesthetic agent, recently has being used as a novel, fast acting, and efficacious anti-depressant because of its very unique pharmacological property and efficacy to acutely decrease suicidal ideation. Recent publications have reviewed the latest literature and neurobiological basis of ketamine's rapid action in decreasing depressive symptoms and suicidal ideation. Worldwide, there are approximately 350 million people or $4.3 \%$ of total popula- 
tion are affected by major depressive disorder (MDD), and bipolar disorder is associated with high morbidity and disability rates, with an estimated lifetime prevalence of $14.6 \%$ [23] [24] [25] [26]. The mechanism of this antidepressant effect is thought to be ketamine's antagonism to N-methyl-D-aspartate (NMDA) receptor, with a half-life of about 2 hours. Nor-ketamine, the less potent metabolite of ketamine, has a half-life of about 5 hours. Possible explanations for ketamine's antidepressant effect include its high affinity for NMDA receptors and its unique subunit selectivity of NMDA receptors. Ketamine's antidepressant response lasts beyond its elimination half-life, suggesting that this response is not attributable to ketamine's psycho-mimetic and dissociative properties, which shows promise of ketamine as a novel therapeutic for unipolar and bipolar depression, and the rapidity of ketamine's antidepressant effects together with its efficacy in patients failing to respond to conventional antidepressant treatment has sparked interest in its potential as an anti-suicide treatment [23] [27]. In 1994 Krystal et al. psychotomimetic and other effects (Perceptual, Cognitive, and Neuroendocrine Responses) of intravenous LDK ( 0.1 and $0.5 \mathrm{mg} / \mathrm{kg}$ infused over $40 \mathrm{~min}$ ) were reported in 19 healthy volunteers $(n=19)$ and found with the idea that LDK administration was a good model of schizophrenia [28]. Berman et al. (2000) Placebo-controlled, double-blinded trial to assess the treatment effects of LDK found a marked, early antidepressant effect that was identifiable at 4 hours post-ketamine and that remained at a 72 hours evaluation [29]. Zarate et al. confirmed their positive results with ketamine in the RCT of treatment-resistant major depression; the response and remission rates were $71 \%$ and $29 \%$ one day after LDK $(0.5$ $\mathrm{mg} / \mathrm{kg}$ ) infusion and the antidepressant effect though lessen and $35 \%$ of population had response at least for a 1 week [30]. David et al. 2017 research on LDK for TRD in an academic clinical practice setting found that a single infusion of low-dose ketamine was efficacious and generally well tolerated in the sample population treated in a "naturalistic" clinical context [26] [31]. Theirs retrospective study of evaluating ketamine effect in TRD patient, the response rate in the sample (53.7\%) at 24-hours of the infusion was slightly lower than the average response rate $(61 \%)$ reported at $24-\mathrm{h}$ post infusion, however, an interviewer base rating scale (Montgomery-Asberg Depression Scale (MADRS) and Hamilton Depression Rating Scale (HAM-D)) was used as the primary measure rather than Beck's Depression Inventory (BDI). Ketamine appeared to produce a rapid antidepressant effect and was well tolerated in a naturalistic outpatient community TRD sample with prevalent co-morbidities and concurrent psychiatric medications [31]. Prince RB et al. 2019 RCT reported that single and repeated dose of iv LDK $(0.5 \mathrm{mg} / \mathrm{kg}$ over 40 minute) decrease the measures of suicidality in sample population with TRD [32]. Many evidences have reported the robust antidepressant and anti-suicidal effects of ketamine in treatment of TRD [18] [33] [34]. The Janssen Pharmaceutical Company published the results of the 3 phase study of (S)-ketamine. In phase 2 the administration of esketamine nasal spray showed good efficacy for the rapid reduction in the depressive symptoms in TRD patient [18] [34] [35]. On March 2019, FDA approved esketamine (Spravato-Janssen), an 
$\mathrm{N}$-methyl-D-aspartate (NMDA) receptor antagonist for intranasal treatment (in conjunction with an oral antidepressant) of adults with TRD [18] [34]. Glue P et al. 2019 double-blinded, psychoactive-controlled ascending dose (0.25, 0.5, 1 $\mathrm{mg} / \mathrm{kg}$ ) study reported that ascending dose LDK has potential effect for patients with treatment resistance generalized anxiety disorder and that was identifiable at an hour of post-ketamine, and persisted for up to 1 week [36] [37]. All of these studies provided new target therapy for TRD and other psychological disorders under persistence follow-up, assessment along with monitoring of all safety measures. Despite of this, there are much ongoing clinical researches on various of these topics.

\section{Analgesic Action of Ketamine in Emergency Departments (ED)}

Pain is the most common symptom prompting an emergency department visit and emergency physicians often need to control violent, psychotic, or intoxicated patients who present a danger to themselves and hospital personnel but it's hard to control the acutely agitated patient. Benzodiazepines and typical antipsychotics such as haloperidol are the most commonly used sedative agents, but have limitations including slow onset, respiratory depression, and variability in clinical response. Recent studies have shown the efficacy of ketamine for sedation in the prehospital setting and as a rescue medication in emergency department (ED). For patients who failed previous sedation attempts, ketamine is effective as a first line sedative agent for agitated patients in the ED [1]. Ketamine has distinct pharmacologic ability with a unique mechanism of action, which is safe and effective for treating pain in Emergency Department. Ketamine possesses potent analgesic, amnestic, and anesthetic properties. It is a non-competitive N-methyl-D-aspartate (NMDA) and glutamate receptor antagonist that decreases central sensitization and "wind-up" phenomenon at the level of the spinal cord (dorsal ganglion) and central nervous system and provides anti-hyperalgesia, anti-allodynia, and anti-tolerance [38] [39] [40] [41] [42]. The NMDA receptor antagonist results to decrease acute pain, opioid tolerance, opioid-induced hyperalgesia, as well as persistent chronic (allodynia) and neuropathic pain. When ketamine served as a first line agent for sedation of agitation in emergency department patients, significantly more patients receiving ketamine were found to have their agitation controlled. Ketamine given intravenously in low (sub-dissociative, analgesic) doses (Table 1) $(0.1-0.3 \mathrm{mg} / \mathrm{kg})$ over a period of $0.5-1$ hour provides effective analgesia with cognition or consciousness and accompanied by preservation of protective airway reflexes, spontaneous respiration and hemodynamics stability in patients with Injury Severity Score $>8$. Ketamine was associated with a significantly better effect on the systolic blood pressure compared to opioid analgesia. Low dose ketamine (LDK) has emerged as a safe and effective non-opioid alternative for patients with chronic or refractory as well as acute pain. Ketamine has been used to control agitation in prehospital, aeromedical, military, and ED settings in highly agitated and violent emergency department patients. Intravenous 
sub-dissociative dose ketamine is given as a short infusion for sedating agent [9] [40] [41] [42] [43]. Based on agitation score measured at 5-, 10- and 15-min after administration of medications, patients received ketamine were less agitated than other standard medication group. Ketamine appeared to be faster in controlling agitation thanstandard ED medication like benzodiazepines and haloperidol [38]. Visual Analogue Scale (VAS)measurement was used to patients, who needed analgesia prior to an awake procedure, the VAS reduction was 3.5 points for ketamine and 3.1 points for morphine [9] [41]. LDK is recognized as a viable adjuvant and alternative to opioid analgesics in patients at high risk of adverse reactions to opioids and when other non-opioid drugs (such as non-steroidal anti-inflammatory drugs) have failed [38] [39] [40] [41]. For the control of moderate to severe acute pain, $\operatorname{LKD}(0.15-0.3 \mathrm{mg} / \mathrm{kg})$ gives an alternative option for a standard care with morphine alone. Compared with morphine alone, LDK/SDDK had the advantage of reducing pain intensity within 2 hours, Francesca L. Beaudoin $\mathrm{MD}, \mathrm{MS}$ and his colleagues also suggested that $0.3 \mathrm{mg} / \mathrm{kg}$ might be more effective than $0.15 \mathrm{mg} / \mathrm{kg}$. In compared with other standard treatment, LDK seemed to be a reliable analgesic adjuvant for morphine in the treatment of moderate to severe acute pain. There were no serious adverse events occurred, however emergency care providers should be aware that LDK might cause irritability and dizziness [43]. For management of moderate to severe acute pain in emergency department, LDK/SDDK in combination with opioids resulted in successful improvement of pain. When LDK and opioids were used together, the dosage and volume of opioids could be decreased, and the adverse effects of opioids could also be decreased. $0.2 \mathrm{mg} / \mathrm{kg}$ of ketamine was enough to reduce $25 \%$ of opioids consumption over 30 minutes [42]. Ketamine might induce untoward neuropsychiatric adverse effects. These adverse reactions seemed to be mild and transient under cellular ion doses. Emergency physicians should inform patients about potential side effects and avoid ketamine in the treatment of transient mental disorders caused by potential mental disorders or drug abuse. Ketamine should be managed in accordance with established department protocols and procedures [44].

\section{Conclusion}

Ketamine is an "old" drug with emerging clinical implications because of its unique character (NMDA receptor antagonism and also interacts with $\mathrm{Mu}(\mu)$, kappa $(\kappa)$, and delta $(\delta)$ opioids receptors, as well as the monoaminergic receptors, muscarinic receptors and voltage-sensitive calcium channels. In this review various new uses of ketamine have been shown, mainly related to its NMDAR antagonism and the clinical implementation and significance of low dose/sub dissociative dose of ketamine. In future, beyond being used as the adjuvant general anesthesia, it also can be used as a rapid acting antidepressant and anti-suicidal agent for mental disorders, and adjuvant analgesia to avoid potential risk and side effects of opioids in emergency department and in post-operative care. 


\section{Authors' Contribution}

Yuba Raj Thapa wrote the manuscript. Prof. Ren Quan helped to revise the article.

\section{Acknowledgements}

The authors would like to thank all the doctors of Department of Anesthesiology, Zhongda Hospital of Southeast University for providing all the necessary information required for this study.

\section{Conflicts of Interest}

The authors declare no conflicts of interest regarding the publication of this paper.

\section{References}

[1] Himmelseher, S. and Durieux, M.E. (2005) Ketamine for Perioperative Pain Management. Anesthesiology, 102, 211-220.

https://doi.org/10.1097/00000542-200501000-00030

[2] Reynolds, S. (2017) Ketamine: Not Just for Pediatric Sedation? Clinical Pediatric Emergency Medicine, 18, 286-291. https://doi.org/10.1016/j.cpem.2017.09.008

[3] Covvey, J.R. and Lowe, D.K. (2012) Intravenous Ketamine for Treatment-Resistant Major Depressive Disorder. Annals of Pharmacotherapy, 46, 117-123. https://doi.org/10.1345/aph.1Q371

[4] Motov, S., et al. (2018) Continuous Intravenous Sub-Dissociative Dose Ketamine Infusion for Managing Pain in the Emergency Department. The Western Journal of Emergency Medicine, 19, 559-566. https://doi.org/10.5811/westjem.2017.12.36174

[5] Abdallah, C.G., Averill, L.A. and Krystal, J.H. (2015) Ketamine as a Promising Prototype for a New Generation of Rapid-Acting Antidepressants. Annals of the New York Academy of Sciences, 1344, 66-77. https://doi.org/10.1111/nyas.12718

[6] Jonkman, K., Dahan, A., van de Donk, T., Aarts, L., Niesters, M. and van Velzen, M. (2017) Ketamine for Pain. F1000Research, 6, F1000. https://doi.org/10.12688/f1000research.11372.1

[7] Niesters, M., Martini, C. and Dahan, A. (2014) Ketamine for Chronic Pain: Risks and Benefits. British Journal of Clinical Pharmacology, 77, 357-367. https://doi.org/10.1111/bcp.12094

[8] Bell, R.F., Dahl, J.B., Moore, R.A. and Kalso, E. (2005) Peri-Operative Ketamine for Acute Post-Operative Pain: A Quantitative and Qualitative Systematic Review (Cochrane Review). Acta Anaesthesiologica Scandinavica, 49, 1405-1428. https://doi.org/10.1111/j.1399-6576.2005.00814.x

[9] Lee, E.N. and Lee, J.H. (2016) The Effects of Low-Dose Ketamine on Acute Pain in an Emergency Setting: A Systematic Review and Meta-Analysis. PLoS ONE, 11, e0165461. https://doi.org/10.1371/journal.pone.0165461

[10] Dahmani, S., Michelet, D., Abback, P.S., Wood, C., Brasher, C., Nivoche, Y. and Mantz, J. (2011) Ketamine for Perioperative Pain Management in Children: A Meta-Analysis of Published Studies. Pediatric Anesthesia, 21, 636-652. https://doi.org/10.1111/j.1460-9592.2011.03566.x

[11] McNicol, E.D., Schumann, R. and Haroutounian, S. (2014) A Systematic Review and Meta-Analysis of Ketamine for the Prevention of Persistent Post-Surgical Pain. Acta Anaesthesiologica Scandinavica, 58, 1199-1213. 
https://doi.org/10.1111/aas.12377

[12] Golembiewski, J. (2017) Ketamine What Is Old Is New Again. Journal of PeriAnesthesia Nursing, 32, 660-663. https://doi.org/10.1016/j.jopan.2017.09.003

[13] Radvansky, B.M., Shah, K., Parikh, A., Sifonios, A.N., Le, V. and Eloy, J.D. (2015) Role of Ketamine in Acute Postoperative Pain Management: A Narrative Review. BioMed Research International, 2015, Article ID: 749837. https://doi.org/10.1155/2015/749837

[14] Rascón-Martínez, D.M., et al. (2018) Advantages of Ketamine as a Perioperative Analgesic. Revista Médica del Hospital General de México, 81, 253-261. https://doi.org/10.1016/j.hgmx.2016.10.007

[15] Jouguelet-Lacoste, J., La Colla, L., Schilling, D. and Chelly, J.E. (2015) The Use of Intravenous Infusion or Single Dose of Low-Dose Ketamine for Postoperative Analgesia: A Review of the Current Literature. Pain Medications, 16, 383-403. https://doi.org/10.1111/pme.12619

[16] Soto, E., Stewart, D.R., Mannes, A.J., Ruppert, S.L., Baker, K., Zlott, D., Handel, D. and Berger, A.M. (2012) Oral Ketamine in the Palliative Care Setting: A Review of the Literature and Case Report of a Patient with Neurofibromatosis Type 1 and Glomus Tumor-Associated Complex Regional Pain Syndrome. American Journal of Hospice and Palliative Care, 29, 308-317. https://doi.org/10.1177/1049909111416345

[17] Hawksworth, C., et al. (1998) Intrathecal Anesthesia with Ketamine. Regional Anesthesia \& Pain Medicine, 23, 283-288. https://doi.org/10.1097/00115550-199823030-00010

[18] Daly, E.J., Singh, J.B., Fedgchin, M., Cooper, K., Lim, P., Shelton, R.C., Thase, M.E., Winokur, A., Van Nueten, L., Manji, H., et al. (2018) Efficacy and Safety of Intranasal Esketamine Adjunctive to Oral Antidepressant Therapy in Treatment-Resistant Depression: A Randomized Clinical Trial. JAMA Psychiatry, 75, 139-148. https://doi.org/10.1001/jamapsychiatry.2017.3739

[19] Huge, V., Lauchart, M., Magerl, W., Schelling, G., Beyer, A., Thieme, D. and Azad, S.C. (2010) Effects of Low-Dose Intranasal (S)-Ketamine in Patients with Neuropathic Pain. European Journal of Pain, 14, 387-394. https://doi.org/10.1016/j.ejpain.2009.08.002

[20] Laskowski, K., Stirling, A., McKay, W.P. and Lim, H.J. (2011) A Systematic Review of Intravenous Ketamine for Postoperative Analgesia. Canadian Journal of Anesthesia, 58, 911-923. https://doi.org/10.1007/s12630-011-9560-0

[21] Billy Sin, T.T., et al. (2017) The Use of Ketamine for Acute Treatment of Pain: A Randomized, Double-Blind, Placebo-Controlled Trial. Journal of Emergency Medicine, 52, 601-608. https://doi.org/10.1016/j.jemermed.2016.12.039

[22] Zhu, J., Xie, H., Zhang, L., Chang, L. and Chen, P. (2018) Efficiency and Safety of Ketamine for Pain Relief after Laparoscopic Cholecystectomy: A Meta-Analysis from Randomized Controlled Trials. International Journal of Surgery, 49, 1-9. https://doi.org/10.1016/j.ijsu.2017.11.031

[23] Price, R.B. and Mathew, S.J. (2015) Does Ketamine Have Anti-Suicidal Properties? Current Status and Future Directions. CNS Drugs, 29, 181-188. https://doi.org/10.1007/s40263-015-0232-4

[24] Bromet, E., Andrade, L.H., Hwang, I., Sampson, N.A., Alonso, J., de Girolamo, G., de Graaf, R., Demyttenaere, K., Hu, C., Iwata, N., et al. (2011) Cross-National Epidemiology of DSM-IV Major Depressive Episode. BMC Medicine, 9, Article No. 90. https://doi.org/10.1186/1741-7015-9-90

[25] Oremus, C., Oremus, M., McNeely, H., Losier, B., Parlar, M., King, M., Hasey, G., 
Fervaha, G., Graham, A.C., Gregory, C., et al. (2015) Effects of Electroconvulsive Therapy on Cognitive Functioning in Patients with Depression: Protocol for a Systematic Review and Meta-Analysis. BMJ Open, 5, e006966.

https://doi.org/10.1136/bmjopen-2014-006966

[26] Brooke, S.J., Galvez, V., Shelker, W. and Loo, C.K. (2018) Side-Effects Associated with Ketamine Use in Depression: A Systematic Review. The Lancet Psychiatry, 5, 65-78. https://doi.org/10.1016/S2215-0366(17)30272-9

[27] Li, N., Lee, B., Liu, R.J., Banasr, M., Dwyer, J.M., Iwata, M., Li, X.Y., Aghajanian, G. and Duman, R.S. (2010) mTOR-Dependent Synapse Formation Underlies the Rapid Antidepressant Effects of NMDA Antagonists. Science, 329, 959-964.

https://doi.org/10.1126/science.1190287

[28] Krystal, J.H., Karper, L.P., Seibyl, J.P., Freeman, G.K., Delaney, R., Bremner, J.D., Heninger, G.R., Bowers, M.B. and Charney, D.S. (1994) Subanesthetic Effects of the Noncompetitive NMDA Antagonist, Ketamine, in Humans. Psychotomimetic, Perceptual, Cognitive, and Neuroendocrine Responses. Archives of General Psychiatry, 51, 199-214. https://doi.org/10.1001/archpsyc.1994.03950030035004

[29] Berman, R.M., Cappiello, A., Anand, A., Oren, D.A., Heninger, G.R., Charney, D.S. and Krystal, J.H. (2000) Antidepressant Effects of Ketamine in Depressed Patients. Biological Psychiatry, 47, 351-354. https://doi.org/10.1016/S0006-3223(99)00230-9

[30] Zarate, C.A., Singh, J.B., Carlson, P.J., Brutsche, N.E., Ameli, R., Luckenbaugh, D.A., Charney, D.S. and Manji, H.K. (2006) A Randomized Trial of an N-methyl-D-aspartate Antagonist in Treatment-Resistant Major Depression. Archives of General Psychiatry, 63, 856-864. https://doi.org/10.1001/archpsyc.63.8.856

[31] Feifel, B.M., Boggie, D. and Lee, K. (2017) Low-Dose Ketamine for Treatment Resistant Depression in an Academic Clinical Practice Setting. Journal of Affective Disorders, 221, 283-288. https://doi.org/10.1016/j.jad.2017.06.043

[32] Price, R.B., Nock, M.K., Charney, D.S. and Mathew, S.J. (2009) Effects of Intravenous Ketamine on Explicit and Implicit Measures of Suicidality in Treatment-Resistant Depression. Biological Psychiatry, 66, 522-526.

https://doi.org/10.1016/j.biopsych.2009.04.029

[33] Arai, Y., Onishi, H., Oishi, K., Takeuchi, H. and Yoshida, O. (1992) Value of Prostate-Specific Antigen Measurements with Newly Developed Enzyme Immunoassay (MARKIT-M PA). Hinyokika Kiyo, 38, 1129-1134.

[34] Hashimoto, K. (2019) Rapid-Acting Antidepressant Ketamine, Its Metabolites and Other Candidates: A Historical Overview and Future Perspective. Psychiatry and Clinical Neurosciences, 73, 613-627. https://doi.org/10.1111/pcn.12902

[35] Fedgchin, M., Trivedi, M., Daly, E.J., Melkote, R., Lane, R., Lim, P., Vitagliano, D., Blier, P., Fava, M., Liebowitz, M., et al. (2019) Efficacy and Safety of Fixed-Dose Esketamine Nasal Spray Combined with a New Oral Antidepressant in Treatment-Resistant Depression: Results of a Randomized, Double-Blind, Active-Controlled Study (TRANSFORM-1). International Journal of Neuropsychopharmacology, 22, 616-630. https://doi.org/10.1093/ijnp/pyz039

[36] Glue, P., Neehoff, S., Sabadel, A., Broughton, L., Le Nedelec, M., Shadli, S., McNaughton, N. and Medlicott, N.J. (2019) Effects of Ketamine in Patients with Treatment-Refractory Generalized Anxiety and Social Anxiety Disorders: Exploratory Double-Blind Psychoactive-Controlled Replication Study. Journal of Psychopharmacology, 34, 267-272. https://doi.org/10.1177/0269881119874457

[37] Jaspersen, D. (1992) The Diagnosis and Therapy of Dieulafoy's Bleeding. Deutsche Medizinische Wochenschrift, 117, 1447-1449.

https://doi.org/10.1055/s-2008-1062463 
[38] JeffRiddella, A., Bengiamin, R., Hendey, G.W. and Armenian, P. (2017) Ketamine as a First-Line Treatment for Severely Agitated Emergency Department Patients. The American Journal of Emergency Medicine, 35, 1000-1004.

https://doi.org/10.1016/j.ajem.2017.02.026

[39] Pourmand, A., Mazer-Amirshahi, M., Royall, C., Alhawas, R. and Shesser, R. (2017) Low Dose Ketamine Use in the Emergency Department, a New Direction in Pain Management. American Journal of Emergency Medicine, 35, 918-921. https://doi.org/10.1016/j.ajem.2017.03.005

[40] Motov, S., Mai, M., Pushkar, I., Likourezos, A., Drapkin, J., Yasavolian, M., Brady, J., Homel, P. and Fromm, C. (2017) A Prospective Randomized, Double-Dummy Trial Comparing IV Push Low Dose Ketamine to Short Infusion of Low Dose Ketamine for Treatment of Pain in the ED. American Journal of Emergency Medicine, 35, 1095-1100. https://doi.org/10.1016/j.ajem.2017.03.004

[41] Le Cornec, C., Lariby, S., Brenckmann, V., Hardouin, J.B., Ecoffey, C., Le Pottier, M., Fradin, P., Broch, H., Kabbaj, A., Auffret, Y., et al. (2018) Is Intravenously Administered, Subdissociative-Dose KETAmine Non-Inferior to MORPHine for Prehospital Analgesia (The KETAMORPH Study): Study Protocol for a Randomized Controlled Trial. Trials, 19, 260. https://doi.org/10.1186/s13063-018-2634-3

[42] Bowers, K.J., McAllister, K.B., Ray, M. and Heitz, C. (2017) Ketamine as an Adjunct to Opioids for Acute Pain in the Emergency Department: A Randomized Controlled Trial. Academic Emergency Medicine, 24, 676-685. https://doi.org/10.1111/acem.13172

[43] Beaudoin, F.L., Lin, C., Guan, W. and Merchant, R.C. (2014) Low-Dose Ketamine Improves Pain Relief in Patients Receiving Intravenous Opioids for Acute Pain in the Emergency Department: Results of a Randomized, Double-Blind, Clinical Trial. Academic Emergency Medicine, 21, 1193-1202. https://doi.org/10.1111/acem.12510

[44] Todd, K.H. (2017) A Review of Current and Emerging Approaches to Pain Management in the Emergency Department. Pain and Therapy, 6, 193-202. https://doi.org/10.1007/s40122-017-0090-5

\section{Abbreviation}

AMPA: $\alpha$-amino-3-hydroxy-5-methyl-4-isoxazole propionic acid

LDK: Lower dose of ketamine

SDDK: Sub-dissociative dose of ketamine

NMDA: Non-competitive N-methyl-D-aspartate

PACU: Post Anesthetic care unit

PONV: Post-operative nausea and vomiting

ED: Emergency Department

PCA: patient-controlled analgesia

MADRS: Montgomery-Asberg Depression Scale

HAM-D: Hamilton Depression Rating Scale

BDI: Beck's Depression Inventory

VAS: Visual Analogue Scale

MDD: Major depressive disorder

TRD: Treatment-resistant depression 